\title{
ATLAS PROVISIONAL DE LOS PECES CONTINENTALES DE LA PROVINCIA DE ALICANTE (*)
}

\author{
PROVISIONAL ATLAS OF THE FRESHWATER FISHES OF ALICANTE \\ (E. SPAIN) \\ por \\ BENIGNO ELVIRA ${ }^{1}$ E IGNACIO DOADRIO ${ }^{2}$
}

\section{RESUMEN}

Se presentan el catálogo y el atlas provisional de los peces continentales de Alicante. Los datos de distribución se of recen en mapas de reticulado U. T. M. de $10 \times 10 \mathrm{~km}$, donde se distinguen las citas anteriores y posteriores a 1970.

\section{SUMMARY}

The checklist and a provisional atlas of the freshwater fish species occurring in Alicante (E. Spain) are presented. The known records of every species are offered in U. T. M. grid maps. The $10 \times 10 \mathrm{~km}$ squares are labelled with different symbols for pre- and post-1970 records.

Palabras Clave: Atlas, freshwater fishes, Alicante, E. Spain.

\section{INTRODUCCIÓN}

La región valenciana posee una gran tradición pesquera en sus dos vertientes: marina y continental. Sin embargo, actualmente se carece de un catá-

* Este trabajo ha contado con una ayuda del Instituto de Cultura "Juan Gil-Albert" de la Excma. Diputación Provincial de Alicante.

(1) Cátedra de Vertebrados, Facultad de Biología, Universidad Complutense de Madrid, Ciudad Universitaria, 28040 Madrid.

(2) Museo Nacional de Ciencias Naturales, C. S. I. C., C/ José Gutiérrez Abascal 2, 28006 Madrid. 
logo de referencia que comprenda todas las especies de peces de la región. Los tratados clásicos referentes a la ictiofauna fluvial (Cisternas 1877) o en general a la fauna valencianas (Boscá 1916) han quedado obsoletos por el paso del tiempo.

Con relación a Alicante, recientemente se han publicado dos obras que incluyen referencias a los peces marinos: una dedicada a la pesca (Mas y Gil 1979) y otra a los vertebrados marinos (Sánchez-Diana 1982). Por su parte, Juste \& Castillo (1983) revisan la actual legislación pesquera. En rigor, ninguna de estas obras aporta datos originales relativos a la ictiofauna alicantina. Por otro lado, Lloris et al. (1984) en su catálogo de peces del mar catalán incluyen especies y citas procedentes de un área que comprende por el sur hasta la provincia de Alicante.

Los peces de agua dulce de Alicante no han sido objeto hasta ahora de un estudio que permita disponer, al menos de manera preliminar, de un catálogo actualizado de sus especies, por lo que mucho mayor es el desconocimiento de sus áreas de distribución.

En la presente investigación nos hemos propuesto dos objetivos fundamentales: Elaborar un catálogo de los peces que habitan las aguas continentales alicantinas, y en base a los datos de presencia disponibles hasta la fecha, confeccionar mapas de distribución según cuadrículas U. T. M. de $10 \times 10 \mathrm{~km}$ para cada una de las especies.

\section{EL MEdio ACUÁTICo CONTINENTAL EN ALICANTE}

Las aguas interiores con posibilidades de albergar fauna de peces en la provincia alicantina pueden ser de varios tipos: sistemas fluviales, con sus correspondientes tramos embalsados artificialmente; marjales, salinas y otras áreas inundadas, y canales, acequias y balsas de conducción y almacenamiento de agua para riegos.

Todos los ríos alicantinos pertenecen hidrográficamente a la vertiente mediterránea. Los principales sistemas fluviales, enumerados de norte a sur, son (Fig. 1):

El río Serpis, cuyo tramo final discurre por la provincia de Valencia. Incluye el embalse de Beniarrés, situado en territorio alicantino.

El río Bullent, que asimismo nace en Alicante para posteriormente atravesar tierras valencianas.

El río Girona, con el embalse de Isbert.

El río Gorgos o Jalón.

El río Algar, con su afluente el Guadalest donde se erige el embalse de Guadalest.

El río Amadorio, con los embalses de Relleu y Amadorio.

El río Verde o Monegre, con el embalse de Tibi.

El río Vinalopó, con los embalses de Elda y Elche.

Y por último el río Segura, cuyo tramo final discurre por Alicante, después de atravesar las provincias de Jaén, Albacete y Murcia. En su cuenca pueden considerarse incluidos los embalses de El Hondo y de La Pedrera.

Otros sistemas acuáticos que merecen destacarse son los marjales de Pego y las salinas de Santa Pola, La Mata y Torrevieja. La laguna de Salinas no presenta aguas permanentes que permitan su habitación por peces. 
Además transcurren por la provincia, en particular por la zona sur, numerosos canales para riego que pueden ser ocupados por los peces fluviales.

En cuanto a la representación cartográfica, el territorio provincial queda comprendido en un total de ochenta y cuatro cuadrículas completas de $10 \times 10 \mathrm{~km}$ y ocho cuadrículas parciales, correspondiendo éstas a la deformación producida por el huso que divide las zonas $30 \mathrm{~S}$ y $31 \mathrm{~S}$, que discurre por el N. E. de la provincia (Fig. 1). De ellas, sólo una pequeña parte puede albergar ictiofauna de agua dulce, puesto que el resto no posee aguas estables que permitan su ocupación por peces dulceacuícolas.

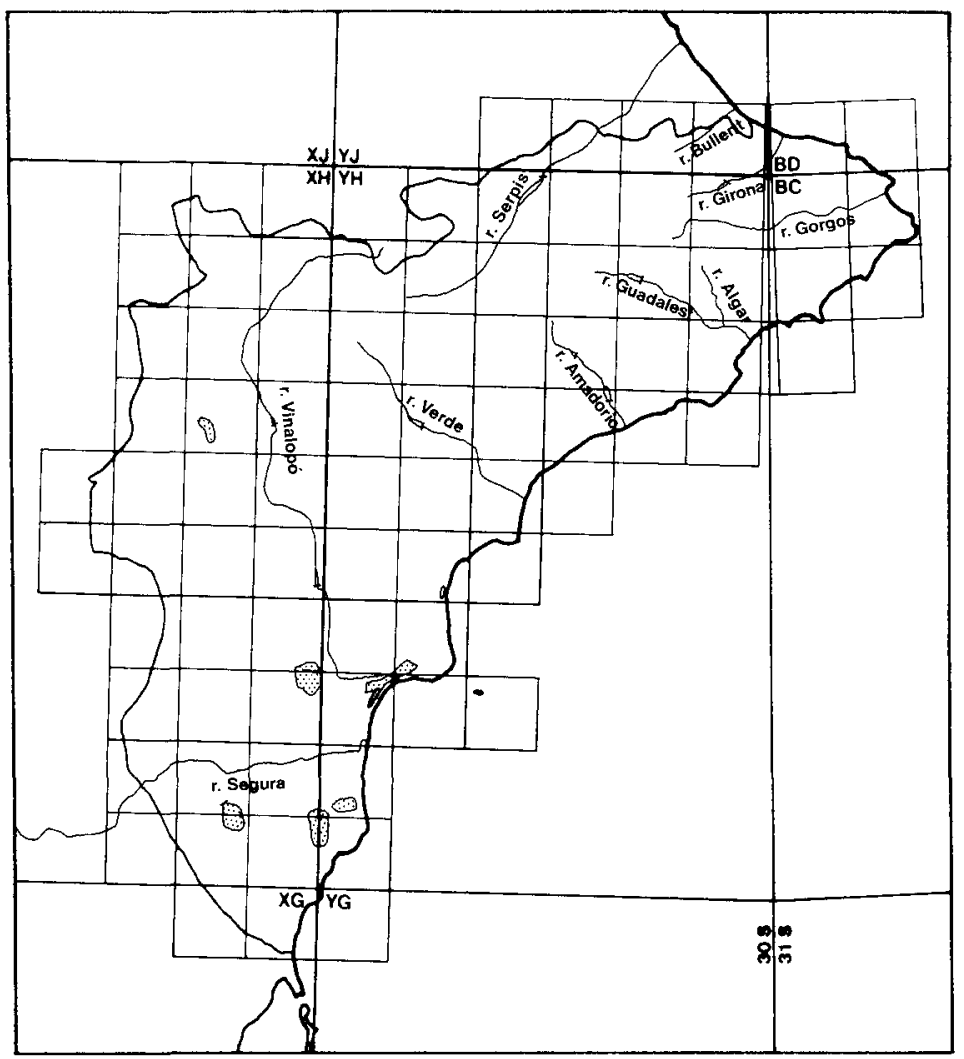

Figura 1.-Mapa hidrográfico de Alicante, con indicación de las cuadrículas U. T. M. de $10 \times 10 \mathrm{~km}$.

\section{MATERIAL Y MÉTODOS}

La elaboración de atlas de flora y fauna tiene ya una cierta tradición en Europa. En el presente caso se han seguido las directrices metodológicas generales propuestas por el Biological Records Centre (Heath \& Perring 1975) y en particular las del Comité para el Cartografiado de los Peces de Agua Dulce 
de España, cuyos proyectos y métodos han sido enunciados por Sostoa et al. (1984). La metodología ha sido ya aplicada en algunos proyectos regionales como los de Galicia (Callejo et al. 1982), Comunidad Autónoma Vasca (Álvarez 1985), Cuenca (Buil et al. 1987) y Madrid (Lobón-Cerviá \& Ávila, en prensa).

En nuestro caso los muestreos ictiológicos se llevaron a cabo mediante un equipo convencional de pesca eléctrica, complementado según los casos por la utilización de artes auxiliares, fundamentalmente trasmallos y salabres. Se efectuaron dos campañas: una en invierno y otra en verano de 1987. Además se utilizaron los datos disponibles obtenidos a partir del material conservado en diversas instituciones científicas: el Museo Nacional de Ciencias Naturales de Madrid, la Unidad de Zoología Aplicada de la Comunidad de Madrid, el Departamento de Zoología (Vertebrados) de la Facultad de Biología de la Universidad de Barcelona, el Departamento de Biología de la Facultad de Ciencias de la Universidad de Alicante, la Estación Ornitológica y Piscícola Experimental «Mata del Fang» del ICONA en Valencia, el Centro Costero del Mar Menor del Instituto Español de Oceanografía en San Pedro del Pinatar (Murcia) y el Departamento de Biología Animal y Ecología de la Facultad de Biología de la Universidad de Murcia. Asimismo, tuvimos en cuenta la información facilitada por la Unidad Forestal de Alicante sobre repoblaciones piscícolas efectuadas en la provincia.

\section{CATÁlogo de ESPECIES}

Familia Anguillidae: Anguilla anguilla

Familia Salmonidae:

Salmo gairdneri

Salmo trutta

Familia Cyprinidae:

Barbus bocagei

Carassius auratus

Cyprinus carpio

Leuciscus pyrenaicus

Familia Cobitidae:

Cobitis maroccana

Familia Cyprinodontidae:

Aphanius iberus

Valencia hispanica

Familia Poeciliidae:

Gambusia affinis

Familia Atherinidae:

Atherina boyeri
Familia Gasterosteidae:

Gasterosteus aculeatus

Familia Syngnathidae:

Syngnathus abaster

Familia Moronidae:

Dicentrarchus labrax

Familia Centrarchidae:

Micropterus salmoides

Familia Mugilidae:

Liza aurata

Liza ramada

Mugil cephalus

Oedalechilus labeo

Familia Blenniidae:

Blennius fluviatilis

Familia Gobiidae:

Pomatoschistus microps

Otras especies de presencia probable o dudosa en la ictiofauna alicantina son: Acipenser sturio (Familia Acipenseridae), Chondrostma toxostoma y Ru- 
tilus arcasii (Familia Cyprinidae) y Chelon labrosus y Liza saliens (Familia Mugilidae).

\section{LA ICTIOFAUNA Y SU DISTRIBUCIÓN}

Se ofrecen a continuación las distribuciones provisionales obtenidas en Alicante para las distintas especies. El orden de exposición de familias sigue a Nelson (1984), dentro de ellas los géneros, especies y subespecies aparecen ordenados alfabéticamente. Se incluyen las especies cuya presencia ha podido ser comprobada, así como aquéllas que han sido citadas en Alicante, pero su presencia real es dudosa o tan sólo probable.

Los nombres vulgares utilizados se tomaron de Lozano-Cabo (1964) y Docavo (1979).

Para todas las especies y subespecies de presencia probada se ofrece un mapa con su área de distribución alicantina normalizada en cuadrículas U. T. M. de $10 \times 10 \mathrm{~km}$. Los círculos negros indican presencia con datos posteriores a 1970, mientras que los círculos blancos indican presencia anterior a 1970 que no ha podido ser comprobada ulteriormente (ver Sostoa et al. 1984). También se indican con un asterisco las cuadrículas correspondientes a lugares donde ha sido introducida la especie.

Familia ACIPENSERIDAE.

Acipenser sturio L., 1758.

Esturión. Nombre valenciano: Esturió.

Pérez-Arcas (1923) cita $A$. sturio de «Alicante», atribuyendo la cita a Asso (1801). En realidad, en la obra de Asso (1801) no se menciona dicha localidad para esta especie. Por lo demás, no conocemos ninguna otra cita del esturión en las costas o ríos alicantinos.

Familia ANGUILLIDAE.

Anguilla anguilla (L., 1758).

Anguila.

Frecuenta las costas de toda la provincia, así como los ríos, canales y aguas interiores que permiten su acceso desde el mar. La hemos encontrado en los ríos Serpis, Bullent, Algar y Segura, así como en el Hondo de Elche (Fig. 2). En cuanto a referencas bibliográficas en Alicante, debemos destacar a Gandolfi (1922 y 1925) que estudia aspectos de su edad y crecimiento en los marjales de Pego.

\section{Familia SALMONIDAE.}

Salmo gairdneri Richardson, 1836.

Trucha arco-iris. Nombre valenciano: Truita arc-iris.

Especie introducida. Según los datos obtenidos en la Unidad Forestal de Alicante, desde 1976 se ha introducido muy localmente en aguas del río Serpis próximas al embalse de Beniarrés, así como en los embalses de Amadorio (donde actualmente no se encuentra), Guadalest y La Pedrera (Fig. 3). No se dispone de datos sobre supervivencia o reproducción de la especie en los lugares donde es introducida, y consecuentemente ignoramos si se ha producido una verdadera aclimatación en aguas alicantinas. 


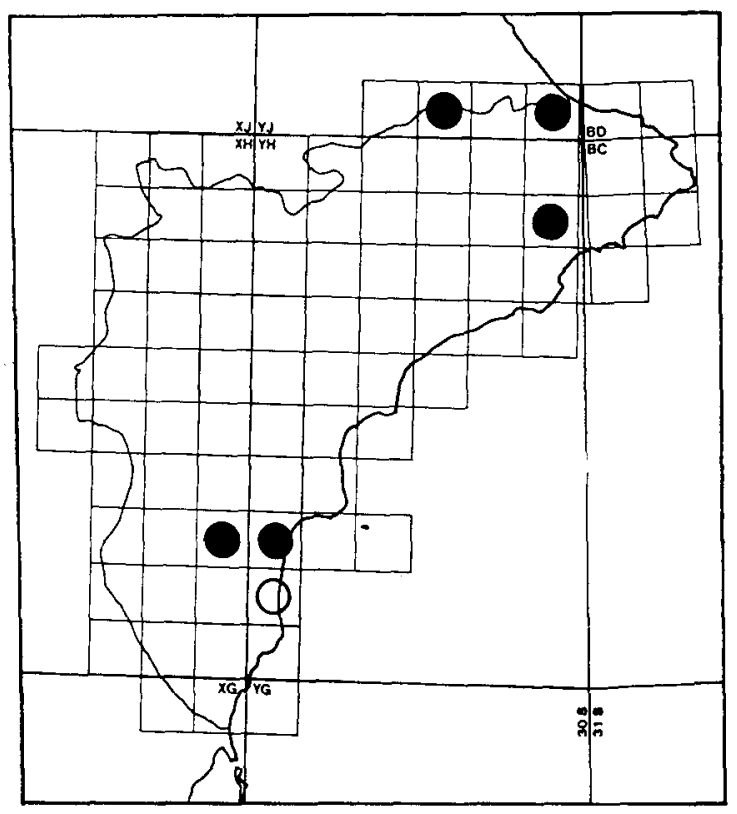

Figura 2.-Distribución de Anguilla anguilla.

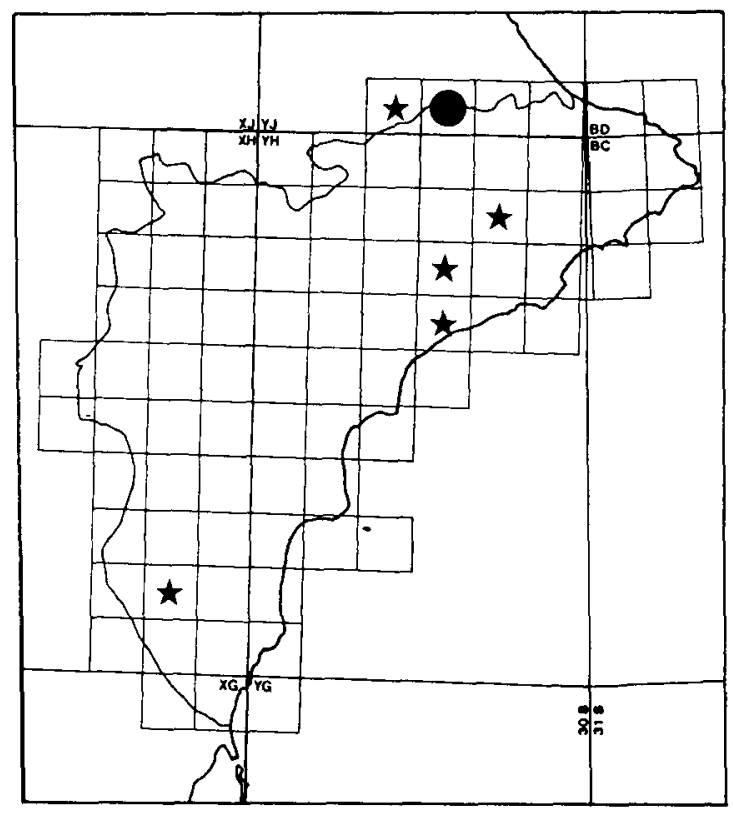

Figura 3.-Distribución de Salmo gairdneri. 
Salmo trutta L., 1758.

Trucha. Nombre valenciano: Truita.

La forma ibérica no migradora correspondería a la denominación Salmo trutta morpha fario L., 1758. Boscá (1916) menciona su presencia y posible extinción en el norte de Alicante: «Hasta hace poco aún existían en Alcoy (río Serpis)..., habiéndolas descastado rápidamente con la nefasta planta matapoll o con la dinamita, etc., cuando podría ser motivo de una industria no despreciable». No conocemos ninguna cita posterior, ni tampoco hemos podido detectar su presencia en nuestros muestreos, por lo que las poblaciones autóctonas de trucha pueden considerarse extinguidas en la provincia de Alicante (Fig. 4).

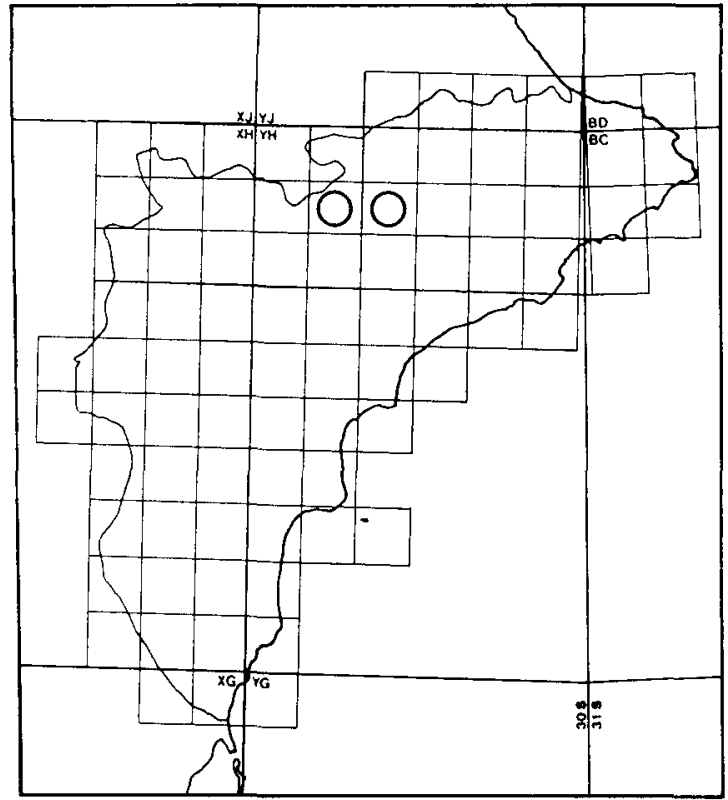

Figura 4.-Distribución de Salmo trutta m. fario.

Familia CYPRINIDAE.

Barbus bocagei Steindachner, 1865.

Barbo ibérico. Nombre valenciano: Barb.

El barbo ibérico es una especie endémica de la península Ibérica, que según Doadrio (1984) presenta tres subespecies: Barbus bocagei bocagei Steindachner, 1865, que vive en el centro de la Península; Barbus bocagei graellsii Steindachner, 1866, en el noreste, y Barbus bocagei sclateri Günther, 1868, en el sur.

En Alicante se encuentran representadas dos subespecies: $B$. bocagei bocagei en el norte de la provincia y $B$. bocagei sclateri en el sur. $B$. bocagei bocagei habita las cuencas de los ríos Serpis y Bullent (Fig. 5); mientras que $B$. 


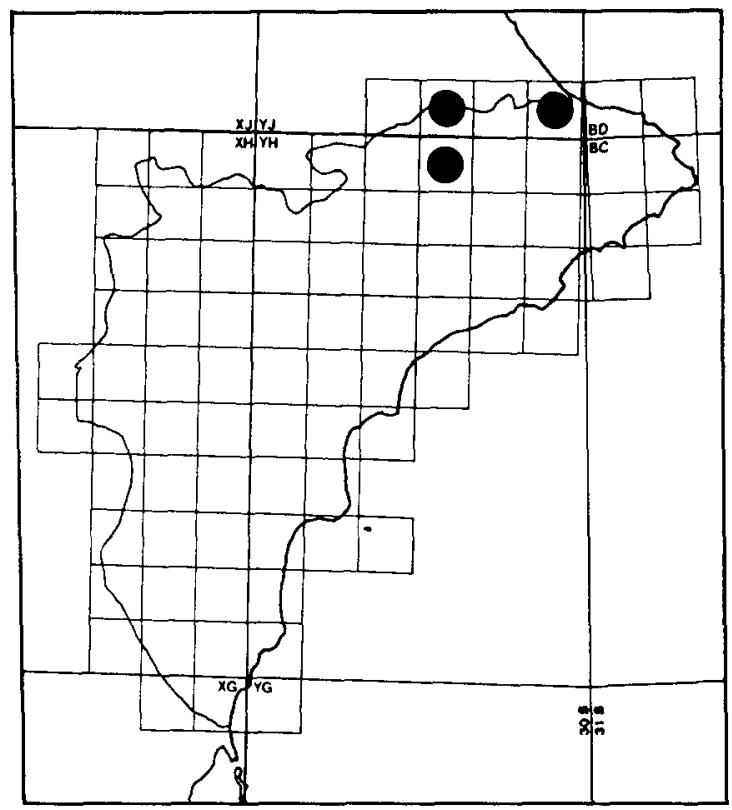

Figura 5.-Distribución de Barbus bocagei bocagei.

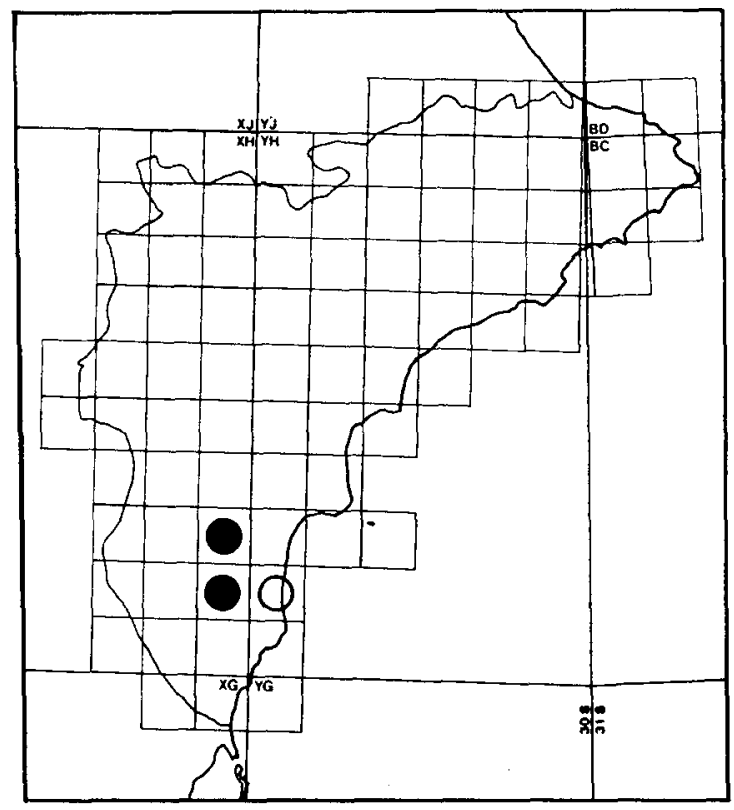

Figura 6.-Distribución de Barbus bocagei sclateri. 
bocagei sclateri vive en el río Segura, donde fue citada por Ugarte (1929) y Vélaz de Medrano \& Ugarte (1930) («río Segura, Guardamar»), además de en el embalse de El Hondo de Elche (Fig. 6). Las poblaciones del río Segura a su paso por la provincia de Alicante se encuentran en franca regresión, debido fundamentalmente a las malas condiciones del agua y a la alta contaminación de la zona (Mas 1986).

Carassius auratus (L., 1758).

Carpín. Nombre valenciano: Carpí.

Especie introducida. En Alicante se encuentra localizada en aguas embalsadas o de escasa corriente, su ambiente característico, en los ríos Algar, Guadalest, Verde y Segura, así como en el embalse de El Hondo de Elche (Fig. 7). Había sido citada en la provincia con anterioridad por Mas (1986) y Doadrio \& Elvira (1986a).

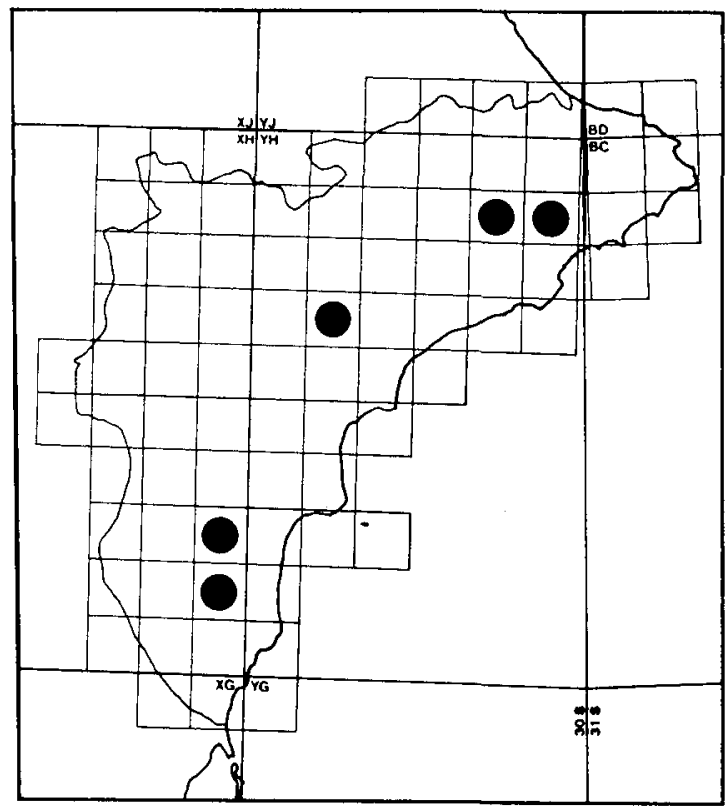

Figura 7.-Distribución de Carassius auratus.

Chondrostoma toxostoma (Vallot, 1837).

Madrilla. Nombres valencianos: Loina, Madrija.

Especie citada por Vélaz de Medrano \& Ugarte (1930): «Segura (Guardamar de Segura: Alicante)», con ejemplares conservados en el Laboratorio de la Fauna Forestal Española, Piscicultura y Ornitología. Los ejemplares no vuelven a ser citados en el catálogo de las colecciones de la Sección de Biología de las Aguas Continentales del Instituto Forestal de Investigaciones y Experiencias (Anónimo 1952), ni se encuentran en la actualidad, como personal- 
mente hemos comprobado, en las colecciones de la Unidad de Zoología Aplicada de la Comunidad de Madrid, donde sucesivamente se han conservado los ejemplares de dicho origen. La mayor parte del material citado por Vélaz de Medrano \& Ugarte (1930) se perdió en el período 1936-1939 (ver Anónimo 1952), por lo que las posibilidades de comprobar la cita son muy remotas, ya que por otra parte nunca ha sido citada ninguna especie de Chondrostoma en la cuenca del río Segura.

Cyprinus carpio L., 1758.

Carpa. Nombre valenciano: Carp.

Especie introducida. La mayoría de los ejemplares que hemos podido estudiar corresponden a la variedad «royal», de la que se efectúan repoblaciones en la provincia desde 1959 (Gutiérrez Calderón /1964/ y archivos de la Unidad Forestal de Alicante). La especie presenta en la provincia una distribución amplia pero localizada en embalses o ríos de poca corriente. Disponemos de datos de su presencia en el río Serpis y en los embalses de Amadorio y Hondo de Elche (Fig. 8).

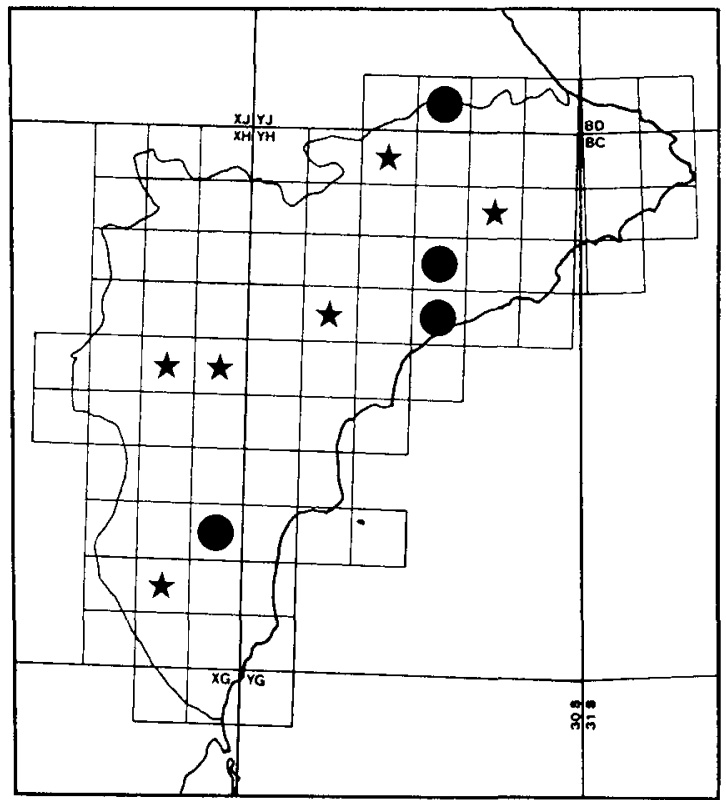

Figura 8.-Distribución de Cyprinus carpio.

Leuciscus pyrenaicus Günther, 1868.

Cachuelo, Cacho. Nombres valencianos: Madrilla, Madrija.

Endemismo ibérico. Se distribuye ampliamente por el centro y sur peninsular (Doadrio 1984 y 1987). En Alicante vive en numerosos cursos fluviales. Se trata del ciprínido más común y ampliamente distribuido en la provincia. 
Se encuentra al menos en las cuencas de los ríos Serpis, Girona, Gorgos, Algar y Guadalest, y Verde, así como en el embalse de El Hondo (Fig. 9). En las colecciones del Museo Nacional de Ciencias Naturales de Madrid se conservan cinco ejemplares del «río Segura en Orihuela, sin fecha» (Doadrio, 1989). Actualmente, la población del bajo Segura se encuentra en claro declive debido a las condiciones ambientales adversas. Así, Mas (1986) no incluye a la especie entre la ictiofauna actual de la cuenca del Segura.

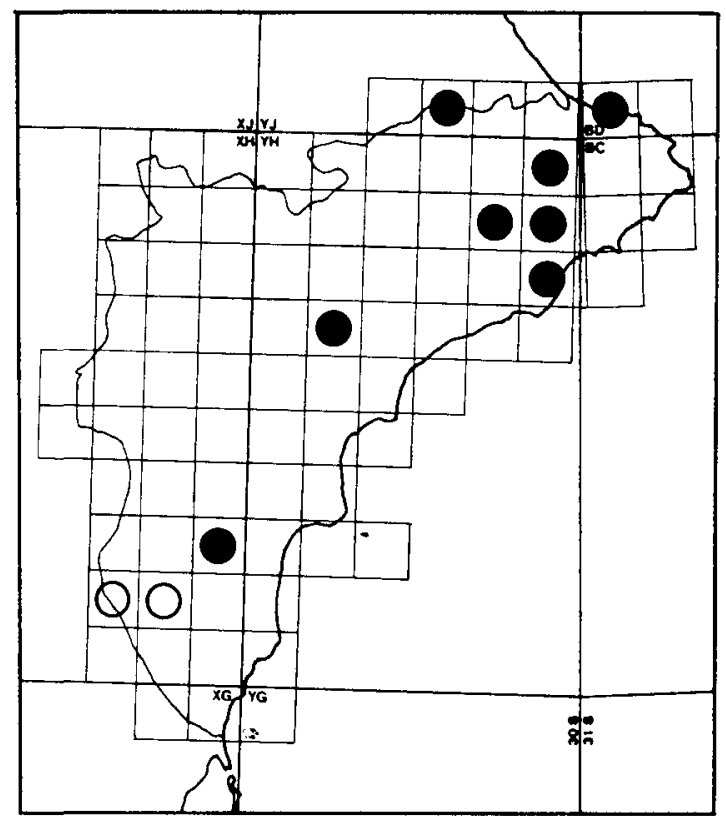

Figura 9.-Distribución de Leuciscus pyrenaicus.

Rutilus arcasii (Steindachner, 1866).

Bermejuela. Nombre valenciano: Madrija.

En las colecciones del Museo Nacional de Ciencias Naturales de Madrid se conservan dos ejemplares de esta especie legados por Boscá del «río Serpis, 26.VI.1914». No fueron citados en el catálogo de Lozano-Rey (1919) pero sí en el de Doadrio (1989), así como por Doadrio \& Elvira (1986b). La presencia de la bermejuela en Alicante es pues dudosa, pues por una parte los ejemplares del río Serpis pueden haber sido colectados en Alicante o en Valencia, y por otra la especie no ha vuelto a ser citada ni la hemos podido detectar en nuestros muestreos en dicha zona.

Familia COBITIDAE.

Cobitis maroccana Pellegrin, 1929.

Colmilleja. Nombres valencianos: Rabosa, Aranya.

Endemismo ibérico y norteafricano. Se distribuye por el centro de la península Ibérica y por el noroeste de Marruecos (Doadrio et al., 1988). En Ali- 
cante sólo la hemos podido detectar en una localidad limítrofe con la provincia de Valencia, que representa el extremo más meridional de su distribución en los ríos de la vertiente mediterránea (Fig. 10). Por. otra parte, en las colecciones de la Unidad de Zoología Aplicada de la Comunidad de Madrid existen ejemplares de colmilleja colectados en «Alicante, 11.I.1971». No se ha podido determinar si proceden de Alicante capital o de la provincia de Alicante, por lo que no han sido incluidos en los mapas de distribución.

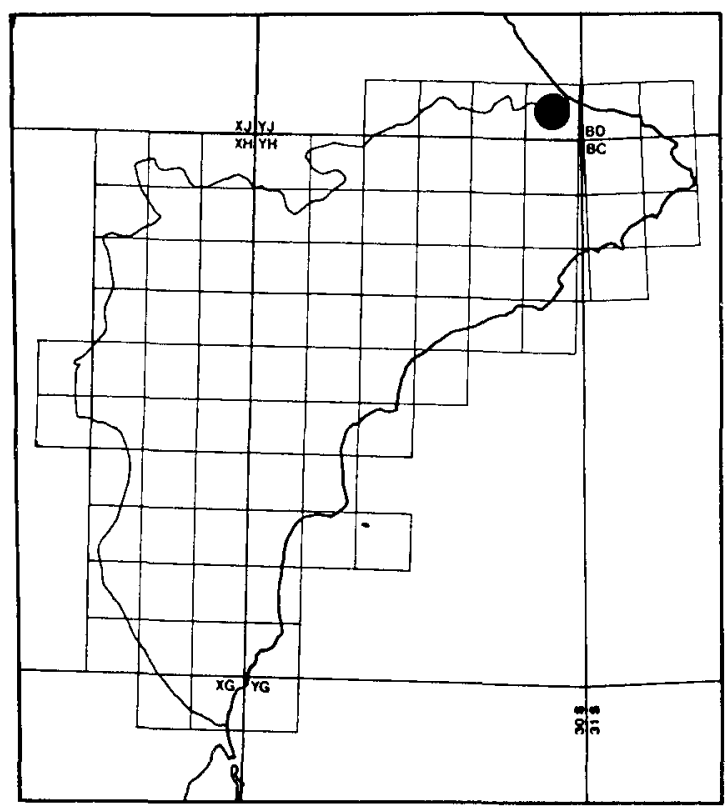

Figura 10.--Distribución de Cobitis maroccana.

Familia CYPRINODONTIDAE.

Aphanius iberus (Valenciennes, 1846).

Nombres valencianos: Fartet, Peixet de sequiol.

Endemismo ibérico y norteafricano. Se distribuye por el litoral ibérico mediterráneo y por el bajo Guadalquivir, así como en algunas localidades de Argelia (Villwock \& Scholl 1982, Sostoa 1984). El fartet se distribuye por diversas localidades de la provincia (Fig. 11). Anteriormente había sido citado por numerosos autores en localidades alicantinas (de Buen 1930, Lozano-Cabo 1958, Mas 1981, Díaz-Luna \& Gómez-Caruana 1983, Gómez-Caruana et al. 1986).

Valencia hispanica (Valenciennes, 1846).

Samarugo. Nombre valenciano: Samaruch.

Endemismo ibérico. Su limitada área de distribución comprende exclusivamente localidades interiores del litoral mediterráneo entre Barcelona y Alicante. Citada por Díaz-Luna \& Gómez-Caruana (1983) y Gómez Caruana et 


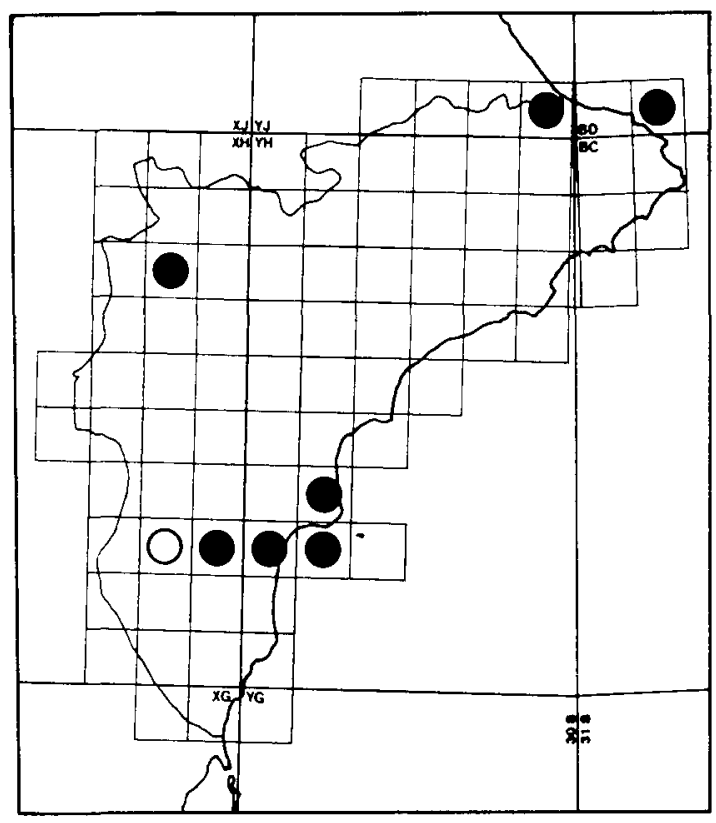

Figura 11.-Distribución de Aphanius iberus.

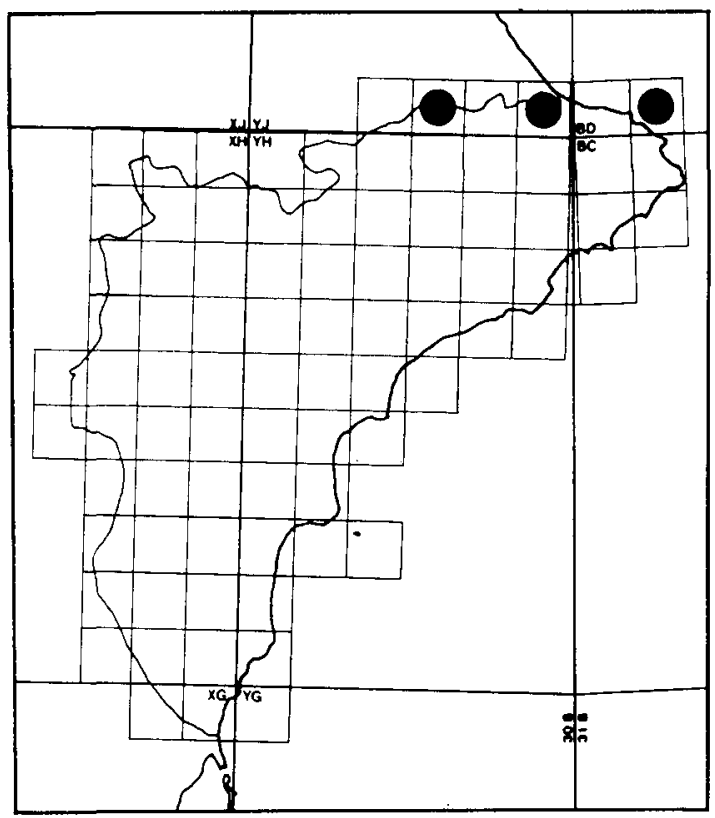

Figura 12.-Distribución de Valencia hispanica. 
al. (1986) en el norte de Alicante, sólo ha podido ser detectada su presencia en tres localidades alicantinas, que representan el límite meridional conocido del área de distribución de la especie (Fig. 12).

Familia POLECILIIDAE.

Gambusia affinis Baird \& Girard, 1853.

Gambusia.

Especie introducida. La subespecie aclimatada en España correspondería a Gambusia affinis holbrooki (Girard, 1859). En Alicante, según Nájera (1946), se introdujo por los Servicios antipalúdicos desde 1943. Las repoblaciones se efectuaron a partir de los criaderos existentes en Orihuela, Alicante y Villajoyosa, en dichas localidades así como en los términos de Elche, Dolores, Rojales y Benidorm. Actualmente se encuentra ampliamente distribuida en los cursos de agua de la provincia, al menos en los ríos Bullent, Racons, Amadorio, Vinalopó y Segura, en las salinas de Santa Pola y en el embalse de El Hondo de Elche (Fig. 13).

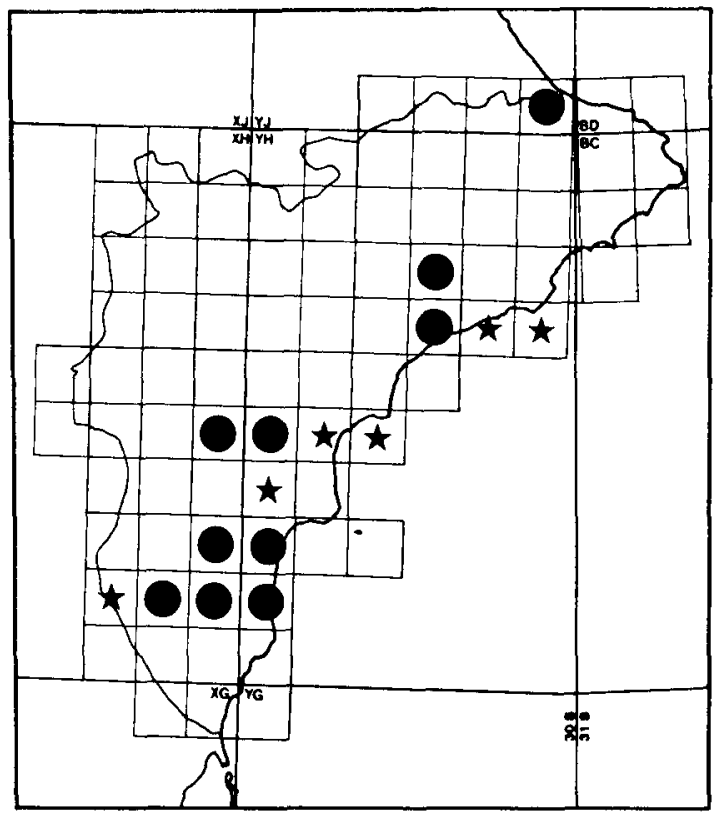

Figura 13.-Distribución de Gambusia affinis holbrooki.

Familia ATHERINIDAE.

Atherina boyeri Risso, 1810.

Pejerrey. Nombres valencianos: Moixó, Moixonet.

Especie eurihalina. Presenta una distribución muy localizada en las aguas interiores alicantinas (Fig. 14). Su presencia en las aguas del río Segura se ve 


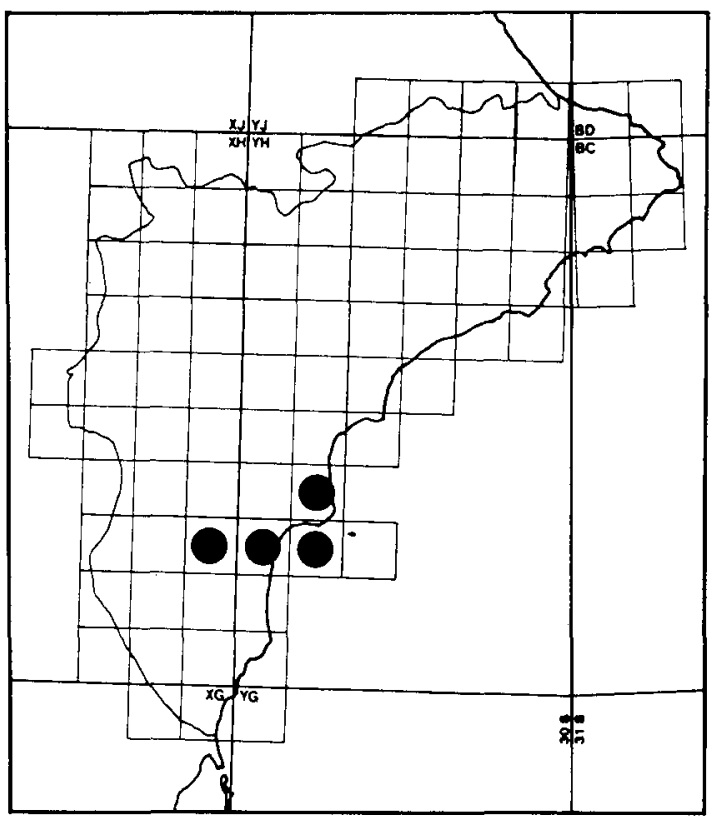

Figura 14.-Distribución de Atherina boyeri.

limitada debido al impedimento que para su migración supone la presa de Guardamar, junto con la mala calidad de las aguas del río (Mas 1986). Lozano-Rey (1935) menciona su existencia en aguas de la huerta de Murcia, donde en la actualidad parece estar ausente (Mas 1986).

Familia GASTEROSTEIDAE.

Gasterosteus aculeatus L., 1758.

Espinoso. Nombres valencianos: Punjoset, Sorellet, Peixet de San Pere.

Especie con poblaciones anadromas y dulceacuícolas. De Buen (1930) cita y figura un ejemplar de espinoso del norte de Alicante (Fig. 15). Según su descripción, el ejemplar correspondería a Gasterosteus aculeatus morpha leiurus, que es la propia de las aguas dulces en la zona del Mediterráneo. En muestreos recientes no ha podido ser comprobada la presencia de espinoso en las aguas alicantinas.

Familia SYNGNATHIDAE.

Syngnathus abaster Risso, 1826.

Aguja de Río. Nombre valenciano: Agulla.

Especie eurihalina, propia de estuarios. Sólo ha podido ser detectada en una localidad interior en el norte de Alicante (Fig. 16). Mas (1986) cita la especie en la desembocadura del río Segura. 


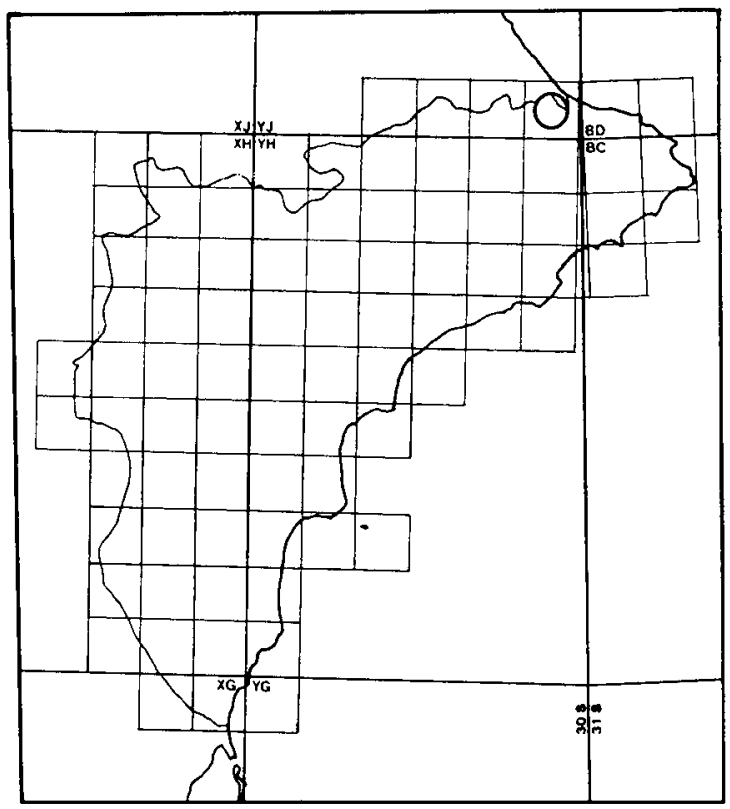

Figura 15.-Distribución de Gasterosteus aculeatus.

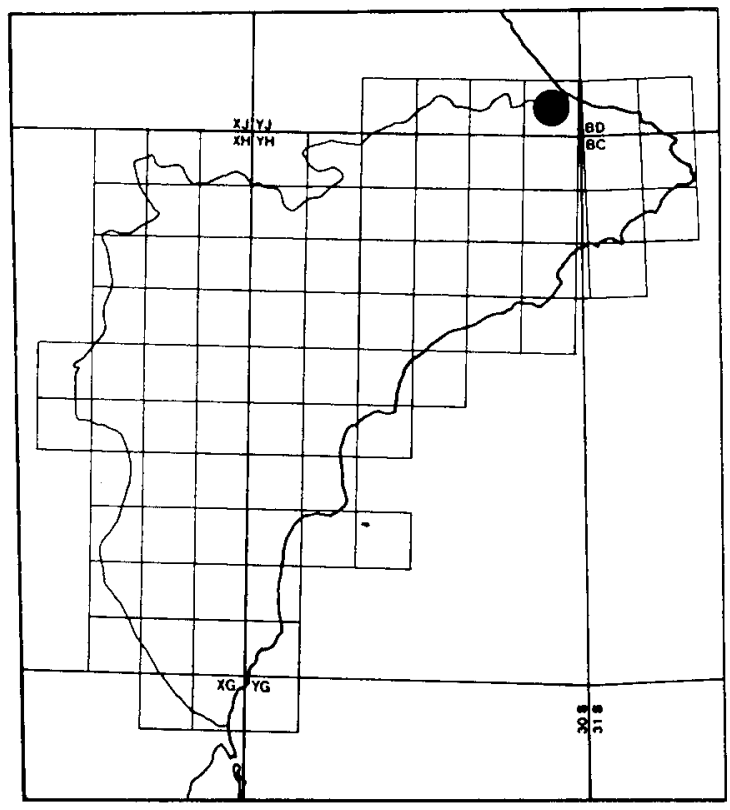

Figura 16.-Distribución de Syngnathus abaster. 
Familia MORONIDAE.

Dicentrarchus labrax (L., 1758).

Lubina. Nombres valencianos: Llobarro, Llop.

Especie eurihalina, muy frecuente en estuarios y zonas intermareales. Presenta una distribución muy localizada en Alicante (Fig. 17). Ha sido citada en aguas interiores alicantinas por Mas (1981 y 1986).

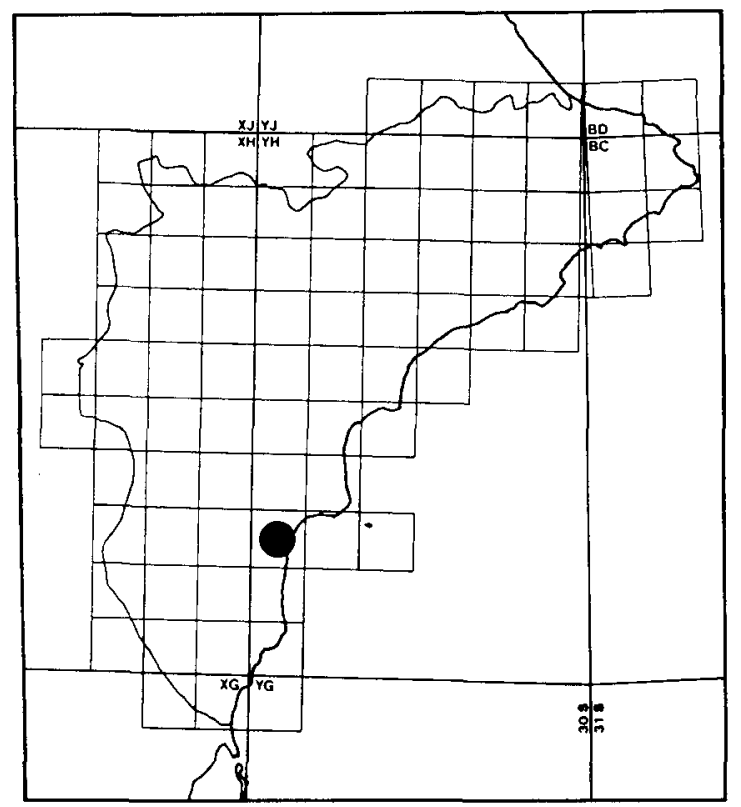

Figura 17.-Distribución de Dicentrarchus labrax.

\section{Familia CENTRARCHIDAE.}

Micropterus salmoides (Lacépède, 1802).

Perca americana o «black-bass».

Especie introducida. En Alicante se efectuaron repoblaciones de la especie desde 1960 en diversos embalses de la provincia (Llatjós 1980). En la actualidad parece presentar una distribución muy localizada (Fig. 18).

Familia MUGILIDAE.

Chelon labrosus (Risso, 1826).

Lisa. Nombres valencianos: Llisa calua blanca, Llisa marsenca.

Especie eurihalina. En el Museo Nacional de Ciencias Naturales de Madrid se conserva un ejemplar de «Alicante, sin fecha», citado como Mugil chelo por Lozano-Rey (1919), como Mugil provensalis por Lozano Rey (1935) y como Chelon labrosus por Matallanas et al. (1981). El ejemplar pudo ser pescado en el litoral alicantino o en sus aguas interiores. Por otra parte, Mas (1986) 


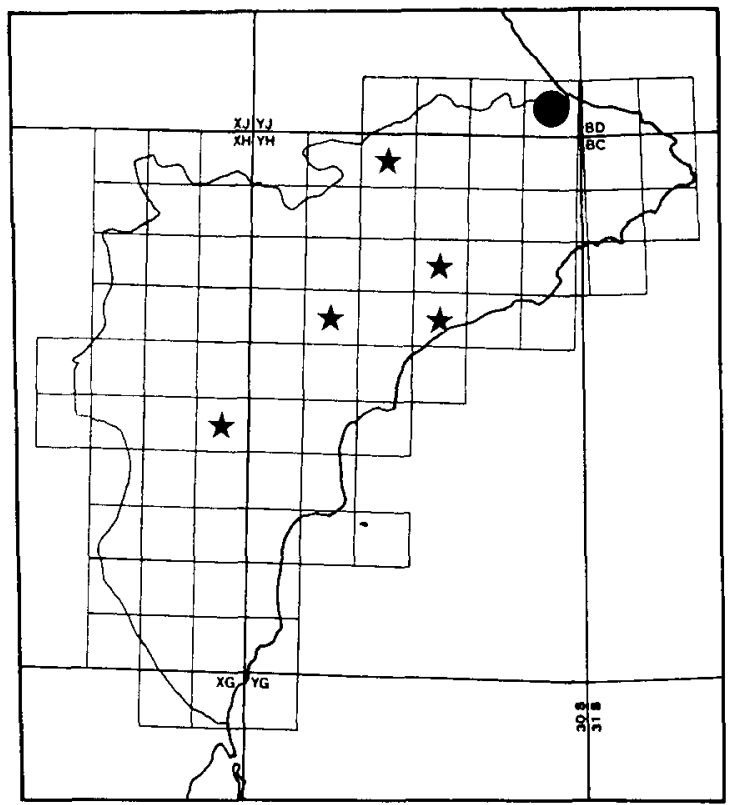

Figura 18.-Distribución de Micropterus salmoides.

cita Chelon labrosus del tramo final del río Segura. Su presencia en aguas interiores alicantinas no ha podido ser comprobada, si bien puede considerarse como probable.

Liza aurata (Risso, 1810).

Galupe. Nombre valenciano: Llisa galtroij.

Especie eurihalina. En las aguas interiores alicantinas la hemos detectado en las salinas de El Saladar, salinas de Santa Pola, Hondo de Elche y tramo final del río Segura (Fig. 19).

Liza ramada (Risso, 1826).

Morragute. Nombres valencianos: Llisa calua negra, Sama.

Especie eurihalina. En las aguas interiores de la provincia sólo la hemos encontrado en el tramo final del río Segura, cerca de su desembocadura (Fig. 20).

Liza saliens (Risso, 1810).

Galúa. Nombre valenciano: Llisa de cap chiquet.

Especie eurihalina. Mas (1986) cita la especie del tramo final del río Segura, y Navarro (1987) del embalse de El Hondo. No hemos podido corroborar hasta ahora su existencia en aguas continentales de Alicante, pero debemos considerar su presencia como probable. 


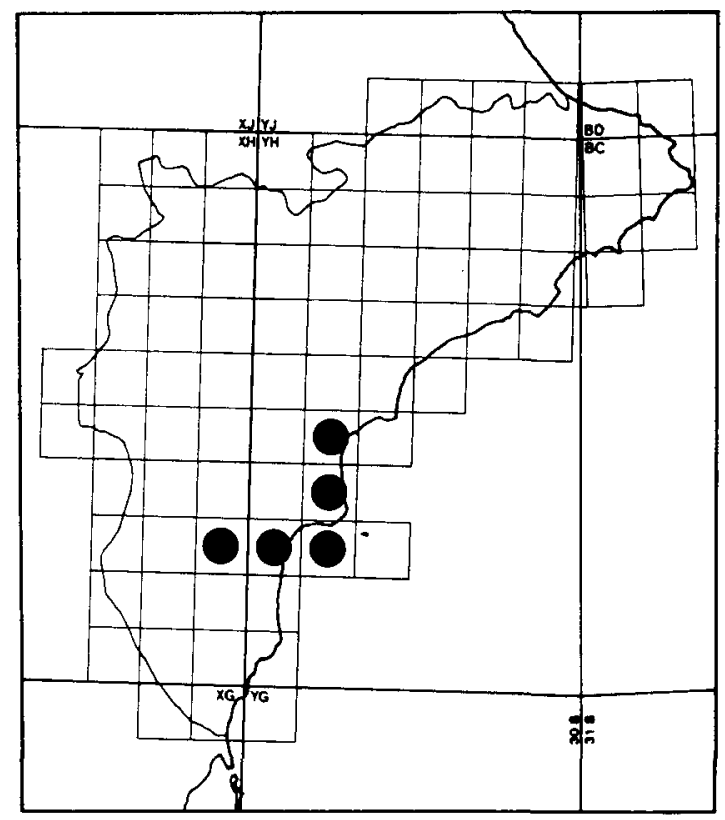

Figura 19.-Distribución de Liza aurata.

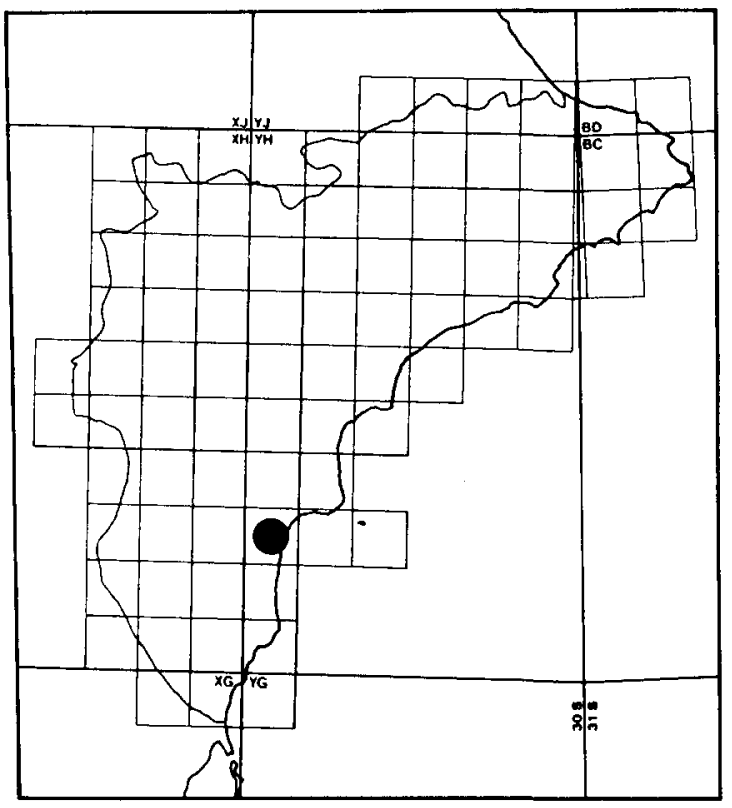

Figura 20.-Distribución de Liza ramada. 
Mugil cephalus L., 1758.

Pardete. Nombres valencianos: Llisa cabuda, Cabeçut.

Especie eurihalina. Citada en Alicante por Vélaz de Medrano \& Ugarte (1930): «río Segura, Guardamar»; se encuentra, además de en el bajo Segura, en las salinas de Santa Pola y en El Hondo de Elche (Fig. 21).

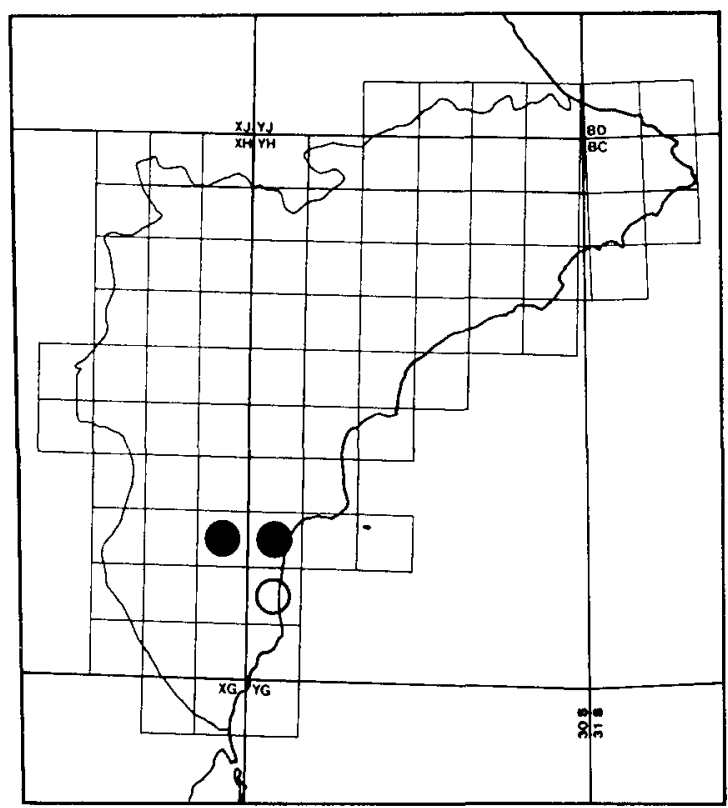

Figura 21.-Distribución de Mugil cephalus.

Oedalechilus labeo (Cuvier, 1829).

Caluga. Nombre valenciano: Llisa morruda.

Especie eurihalina, pero rara en aguas interiores. Sólo la hemos encontrado en el canal de comunicación entre las salinas de La Mata y el mar (Fig. 22). Mas (1986) la cita en el tramo final del río Segura, y Navarro (1987) en el embalse de El Hondo.

Familia BLENNIIDAE.

Blennius fluviatilis Asso, 1784.

Fraile. Nombres valencianos: Aranya, Rabosa.

En el Museo Nacional de Ciencias Naturales de Madrid se conservan nueve ejemplares de Blennius fluviatilis etiquetados «río Segura, Orihuela, Alicante» (Fig. 23). Estos peces no aparecen referenciados en el catálogo de Lozano-Rey (1919). Por otro lado, Anónimo (1952) menciona un ejemplar del «río Segura en Murcia, III.1943». Por nuestra parte, no hemos podido comprobar su presencia actual en el tramo final del río Segura a su paso por Alicante. 


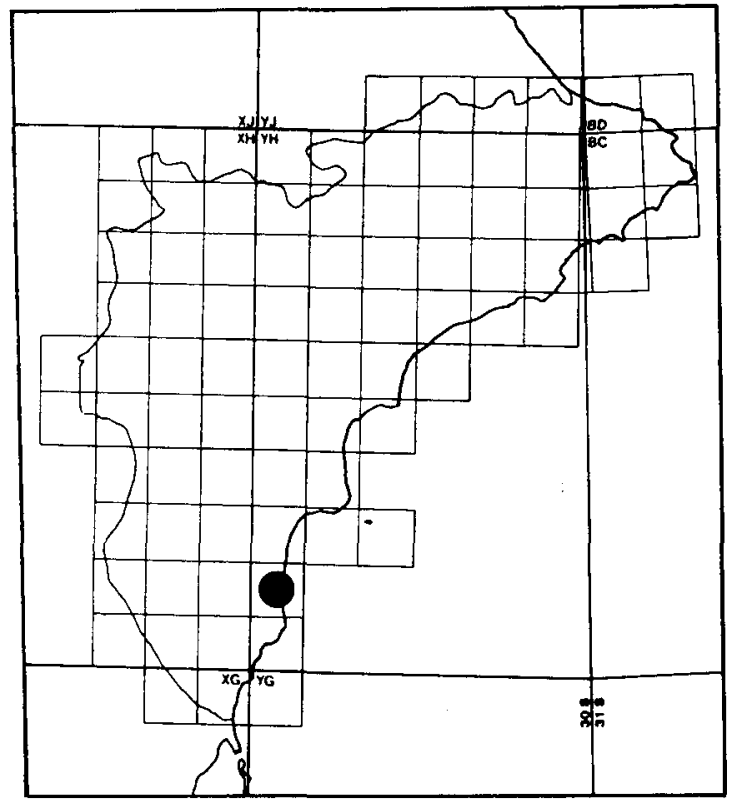

Figura 22.-Distribución de Oedalechilus labeo.

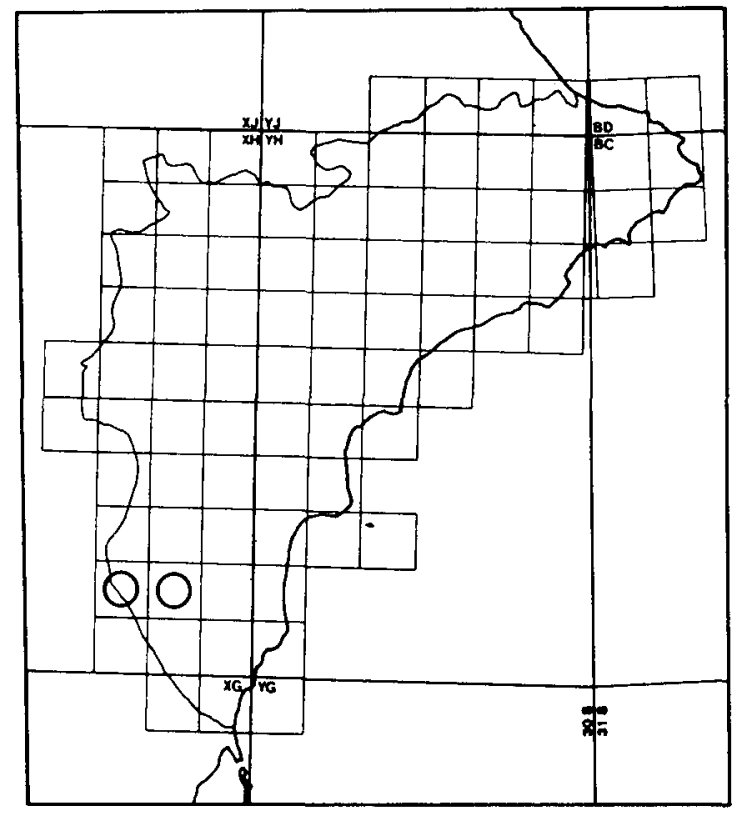

Figura 23.-Distribución de Blennius fluviatilis. 
Familia GOBIIDAE.

Pomatoschistus microps (Kroyer, 1838).

Cabuxino enano. Nombre valenciano: Gobit.

Especie eurihalina, costera, que penetra en los cursos bajos de los ríos o en aguas interiores litorales. En las aguas continentales alicantinas se encuentra al menos en el tramo final del río Segura y en el Hondo de Elche (Fig. 24).

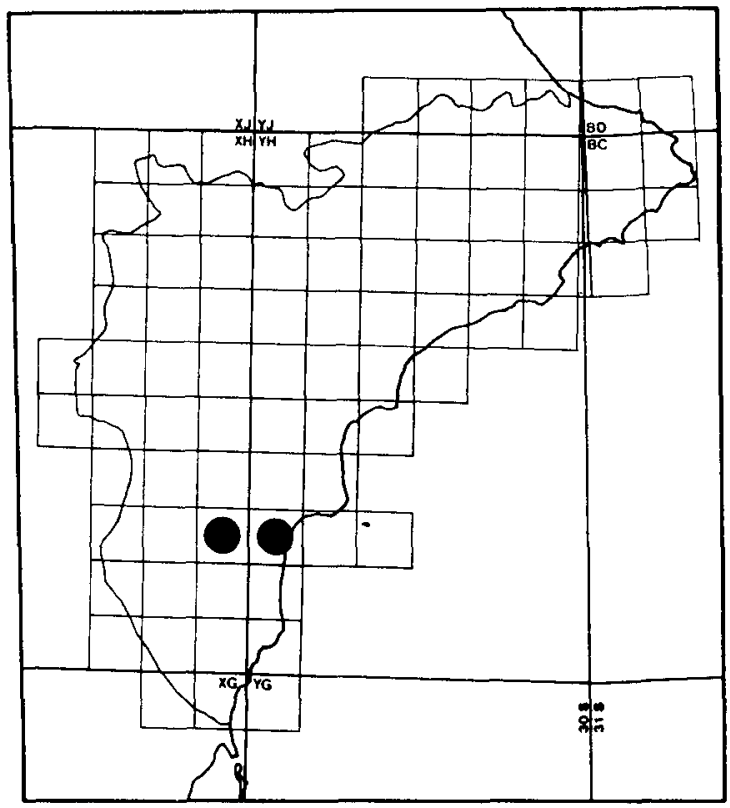

Figura 24.-Distribución de Pomatoschistus microps.

\section{DISCUSIÓN}

La ictiofauna continental alicantina resulta en base a los datos obtenidos relativamente rica en cuanto a número de especies, ventidós, si bien sólo ha podido ser comprobada la presencia actual (datos posteriores a 1970) de diecinueve especies. Además, otras cinco especies han sido consideradas de presencia dudosa o probable.

Diecisiete especies son autóctonas en Alicante, mientras que cinco especies (Salmo gairdneri, Carassius auratus, Cyprinus carpio, Gambusia affinis y Micropterus salmoides) han sido introducidas.

Respecto al origen dulceacuícola de las especies, debemos destacar que solamente seis especies (de ellas sólo tres autóctonas) pertenecen a familias de la división primaria, los peces de agua dulce más característicos.

En cuanto a los aspectos corológicos, todos los sistemas fluviales que presentan aguas permanentes albergan ictiofauna, si bien en la época de estío, cuan- 
do los cursos fluviales quedan interrumpidos, los peces se ven obligados a refugiarse en las balsas o embalses. En conjunto las especies presentan modelos de distribución ralos debido a la escasez y discontinuidad de medios acuáticos habitables.

\section{AGRADECIMIENTOS}

Queremos expresar nuestro más sincero agradecimiento a todas las personas e instituciones que nos han ayudado en la elaboración de este atlas.

En primer lugar a la Conselleria d'Agricultura i Pesca de la Generalitat Valenciana que nos concedió las oportunas autorizaciones para pesca científica. Asimismo, queremos agradecer la ayuda que en todo momento nos fue facilitada por M. Gomis y E. Laguna de la Unidad Forestal de Alicante; así como a J. Jiménez de la Unidad Forestal de Castellón.

E. Seva y A. Ramos, de la Universidad de Alicante; A. Sanz, de la Universidad de Valencia; J. Mas, del Instituto Español de Oceanografía en San Pedro del Pinatar (Murcia), y F. GómezCaruana, de la Estación Ornitológica y Piscícola Experimental del ICONA en Valencia; junto con el personal del Departamento de Biología Animal y Ecología de la Universidad de Murcia, del Departamento de Zoología (Vertebrados) de la Universidad de Barcelona y de la Unidad de Zoologia Aplicada de la Comunidad de Madrid, nos proporcionaron valiosos datos e informaciones sobre distribución de la ictiofauna continental alicantina y nos facilitaron el estudio de sus colec ciones científicas.

J. Fernández nos acompañó en nuestras campañas de recolección.

El proyecto pudo llevarse a cabo en el Museo Nacional de Ciencias Naturales de Madrid, C. S. I. C., gracias a una ayuda a la Investigación del Instituto de Estudios «Juan Gil-Albert» de la Excma. Diputación Provincial de Alicante. 


\section{BIBLIOGRAFÍA}

ÁLVAREZ, J. 1985: Atlas de los peces continentales de Alava, Vizcaya y Guipúzcoa. En: Atlas de los Vertebrados continentales de Álava, Vizcaya y Guipúzcoa. Págs. 25-54, Gobierno Vasco, Bilbao, 336 pág.

ANÓNIMO 1952: Las colecciones de peces de la sección de biología de las aguas continentales. Bol. Inst. For. Inv. y Exp. 63: 1-140.

ASSO, I. 1801: Introducción a la Ichthyología oriental de España. Ann. Soc, Española Hist. Nat. $4(10): 28-52$.

BOSCÁ, A. 1916: Fauna Valenciana. Ed. A. Martín, Barcelona, 131 pág.

BUEN. F. DE 1930: Notas sobre la fauna ictiológica de nuestras aguas dulces. Notas y Res. Inst. Esp. Oceanogr. ser. II. 46: 1-62.

BUIL, J. R.; J. A. FERNÁNDEZ-YUSTE; J. LOZANO \& J. I. NICOLÁS 1987: Datos sobre la distribución de peces en los ríos de la provincia de Cuenca. Ecología 1: 231-245.

CALLEJO, A.; F. CALVIÑO \& J. GUITIÁN 1982: Datos provisionales sobre la distribución de los ciclóstomos y peces en las aguas continentales de Galicia. Bol. Est. Cent. Ecol. 11 (21): 49-54.

CISTERNAS, R. 1877: Ensayo de un catálogo descriptivo de los peces de agua dulce que habitan en la provincia de Valencia. Ann. Soc. Española Hist. Nat. 6: 69-138.

DÍAZ LUNA, J. L. \& F. GÓMEZ-CARUANA 1983: Fartet y samarugo, dos joyas de la ictiofauna ibérica. Trofeo 154: 34-37.

DOADRIO, I. 1984: Relaciones filogenéticas y biogeográficas de los barbos (Barbus Cyprinidae) de la Península Ibérica y aportes corológicos y biogeográficos a su ictiofauna continental. Tesis Doctoral, Universidad Complutense de Madrid, Madrid, 1146 pág.

- 1987: Leuciscus carolitertii n. sp. from the Iberian Peninsula (Pisces: Cyprinidae). Senck. biol. 68(4-6): 301-309.

- 1989: Catálogo de los peces de agua dulce del Museo Nacional de Ciencias Naturales. Familias: Petromyzontidae, Esocidae, Cyprinidae, Catostomidae, Homalopteridae, Cobitidae, Siluridae, Malapteruridae, Ictaluridae, Clariidae y Cyprinodontidae. C. S. I. C., Madrid.

DOADRIO, I. \& B. ELVIRA 1986a: Distribución geográfica actual del género Carassius Jarocki, 1822 (Ostariophysi, Cyprinidae) en España. Misc. Zool. 10: 385-387.

- 1986b: Nuevas localidades de Rutilus arcasii (Steindachner, 1866) (Ostariophysi, Cyprinidae) en España. Misc. Zool. 10: 387-389.

DOADRIO, I.; B. ELVIRA \& P. GARZÓN 1988: Revisión taxonómica y distribución de Cobitis maroccana Pellegrin, 1929 (Osteichthyes, Cobitidae). Doñana. Acta Vert. 15: 156-161.

DOCAVO, I. 1979: La Albufera de Valencia sus peces y sus aves. Institución Alfonso el Magnánimo, Valencia, 240 pág.

GANDOLFI, A. 1922: Edad y crecimiento de algunas anguilas de los marjales de Pego (Alicante). Ibérica 449.

- 1925: La edad de algunas anguilas de las Aguas de Pego. Bol. R. Soc. Española Hist. Nat. 25: 301-306.

GÓMEZ-CARUANA, F.; S. SÁNCHEZ-ARTAL \& S. PEIRÓ-GÓMEZ 1986: Localización geográfica de los ciprinodóntidos endémicos de España. Quercus 22: 22-23.

GUTIÉRREZ-CALDERÓN, E. 1964: Estudio sobre producción de Cyprinus carpio L. var. royal con fines de repoblación. Ministerio de Agricultura. Boletín Técnico. Serie Piscícola. 2: 1-60.

HEATH, J. \& F. PERRING 1975: Biological recording in Europe. Endeavour 34(123): 103-108.

ICONA (ed.) 1986: Lista Roja de los Vertebrados de España. Publicaciones del Ministerio de Agricultura, Pesca y Alimentación, Madrid, 400 pág.

JUSTE, J. \& M. V. CASTILLO 1983: La pesca alicantina ante el actual proceso de revisión del Derecho del Mar. Instituto de Estudios Alicantinos, ser. I., no. 83, Alicante, 188 pág.

LLATJÓS, J. F. 1980: El black bass en España. En: El black bass o perca negra. Particularidades y métodos de pesca, pág 189-202, J. C. Vanson, Ed. Pulide, Barcelona, 204 pág.

LLORIS, D.; J. RUCABADO; LL. DEL CERRO; F. PORTA; M. DEMESTRE \& A. ROIG 1984: Tots els peixos del mar Catalá. I: Llistat de cites i referències. Treballs Soc. Cat. Ict. Herp. 1: $1-200$.

LOBÓN-CERVIÁ, J. \& M. ÁVILA (en prensa): Atlas y distribución de los peces de la Comunidad Autónoma de Madrid. Consejería de Agricultura y Ganadería, Comunidad de Madrid.

LOZANO-CABO, F. 1958: Contribución al conocimiento del Fartet (Aphanius iberus C. et V.) Rev. R. Acad. Cienc. Ex., Fis. y Nat. 52(3): 585-607.

- 1963-1964: Nomenclatura Ictiológica. Nombres científicos y vulgares de los peces españoles. Trab. Inst. Esp. Oceanogr. 31: 1-271.

LOZANO-REY, L. 1919: Los peces de la fauna ibérica en la colección del Museo, en 1 de enero de 1919. Trab. Mus. Nac. Cienc. Nat., ser. zool., 39: 1-112. 
- 1935: Los peces fluviales de España. Mem. Acad. Cienc. Ex., Fis. y Nat., ser. cienc. nat., 5: $1-390$.

MAS, J. 1981: Notas sobre la situación actual de las localidades de ciprinodóntidos y familias afines en el levante de la Península Ibérica. Bol. Inst. Esp. Oceanogr. 6(3): 215-221.

- 1986: La ictiofauna continental de la cuenca del río Segura. Evolución histórica y estado actual. Anales de Biología 8: 3-17.

MAS Y GIL, L. 1979: La Pesca en Alicante (Ensayo para su historia). Publ. Caja de Ahorros Provincial de Alicante, Alicante, 173 pág.

MATALLANAS, J.; M. IBÁÑEZ; D. SAN MILLÁN \& G. RIBA 1981: Catálogo de los Peces Marinos de la Colección del Museo Nacional de Ciencias Naturales de Madrid. Trabajos del Departamento de Zoología, Universidad Autónoma de Barcelona, Barcelona, n. 1, 138 pág.

NÁJERA, L. 1946: La Gambusia holbrookii en España. Las Ciencias 11(4): 837-876.

NAVARRO, J. D. 1987: Estudio sobre las zonas húmedas sudalicantinas: «El Hondo». Libro I. Informe no publicado, 397 pág.

NELSON, J. S. 1984: Fishes of the World. John Wiley \& Sons, Nueva York, $2 .^{a}$ ed., 523 pág.

PÉREZ-ARCAS, L. 1921-1923: Ictiología Ibérica, o sea Catálogo de los peces marinos y de agua dulce que habitan o frecuentan las costas de la Península Ibérica. Rev. R. Acad. Cienc. Ex. Fis. y Nat. 19: 355-546.

SÁNCHEZ-DIANA, A. 1982: Vertebrados marinos. Cuadernos de fauna alicantina. Instituto de Estudios Alicantinos, ser. II, no. 3, Alicante, 78 pág.

SOSTOA, A. DE; F. J. DE SOSTOA; J. LOBÓN-CERVIÁ; B. ELVIRA; J. A. HERNANDO; I. DOADRIO \& M. ÁVILA 1984: Atlas y distribución de los peces de agua dulce de España: el proyecto, métodos y resultados preliminares. Bol. Est. Cent. Ecol. 13(25): 75-81.

SOSTOA, F. J. DE 1984: Biología de Aphanius iberus (Cuv. et Val., 1846) en el delta del Ebro ( $N E$ ibérico). Tesina de Liceciatura, Universidad de Barcelona, Barcelona, 224 pág.

UGARTE, J. 1929: Peces de agua dulce. Contribución a la formación de su Catálogo. Rev. Biol. For. y Limnol. I. ser. A. 1: 54-70.

VÉLAZ DE MEDRANO, L. \& J. UGARTE 1930: Contribución a la formación del catálogo ictiológico de nuestras aguas continentales. Rev. Biol. For. y Limnol. II. ser. A 3: 25-52.

VILLWOCK, W. \& A. SCHOLL 1982: Ergänzende Mitteilungen über Aphanius aus der Oase Azraq/Jordanien sowie Betrachtungen zum taxonomischen Status eines neuen $A$. iberus (Cyprinodontidae: Pisces) aus dem Oued Zousfana, Igli/Nordwest-Algerien. Mitt. hamb. zool. Mus. Inst. 79: 267-271. 